\title{
YEMENI GIRL'S CHALLENGES OF EDUCATION AGAINST THE RESTRICTIONS OF CUSTOMS AND TRADITIONS
}

\section{Prof. Khadija Anasse ${ }^{1}$ Dr. Mohammed Ali Hamoud Ali AL- dyashi Mohammed Abdo Ali AL- Dhahra ${ }^{3}$}

Ibn Tofail University - Morocco

N.I.A.S - Aden University - Yemen

Research Scholar at Ibn Tofail University - Faculty of Languages, literatures and arts -Morocco

HNSJ, 2021, 2(12); https://doi.org/10.53796/hnsj21215

Published at 01/12/2021

Accepted at 23/11/2021

\begin{abstract}
Yemen, as a developing country, suffers many problems, among them the problem of education in general and girls' education in particular one. Some international reports on education show that Yemen is considered to have one of the widest gender gaps, and although there have been sustained efforts to increase the percentage of girls in school however, this did not achieve the desired hope. Yemeni girls' education is still a fundamental issue of discussion and a subject of controversy to get out of this crisis that interests Yemeni as well the international organizations, especially since customs and traditions are among the most important restrictions and obstacles facing Yemeni girls' education. Hence, this article is just an attempt to display Yemeni Girl's challenges of education.
\end{abstract}

Key Words: Yemeni girl's education, restrictions, challenges, customs and traditions. 


\section{Introduction}

Yemeni girls' education faces many challenges. Challenges are concerned to weak capabilities of Yemen, which has not yet been able to build schools in some remote areas, as well as challenges related to customs and traditions that still consider the girls' education as a shame. Educational reports do not reflect the reality of the general situation experienced by the girls themselves. The real image is bleak where people see the girls' education is marginal in their society. For that reason, this article aims to reveal the most common challenges that deprive the Yemeni girls from education in order to find out the real crisis based on the following question:

\section{Could the Yemeni girl overcome the educational crisis in the future?}

The importance of this study at this simple article is to clarify Yemeni girls' educational crisis through relying on the descriptive and analytical approach. Moreover, it will try to expose the efforts which are made by Yemeni government and the educated elite during their attempts to solve the problem of Yemeni girl's education which still a worse up to now.

\section{Short view on Yemen}

Yemen is considered to have one of the widest gender gaps, and although there have been sustained efforts to increase the percentage of girls in school. It has also implemented initiatives and programs for girls' education, but gender parity lags far behind many undeveloped countries. A lot of studies on issues related to girls' education in Yemen, especially in more recent years and most of them are concentrated on an economic challenge considering the Poverty and lack of resources the main factors that Hinder the Yemeni girl's education (Isabella, 2018, P99).

Republic of Yemen is currently a low-income country with an estimated population of 30 million, of which 99 percent are Muslim. It is a relatively newly established country that began as two nations (North Yemen and South Yemen), but became officially unified in 1990.Yemen has suffered many economic, social and political problems since its establishment due to its geographical location that overlooks the most important waterways in the world. These problems are the main reason for its weakness. It also made it enter into conflicts and wars that still exist today. Yemen today suffers from chaos, instability and conflict between many internal parties. Hence, education is become distorted and short - cut process specially for the girls. Moreover, it became absent factor that does not allow for the observation of individual differences and social diversity in addition, the last thing that Yemeni people think about it (Aljazeera.net). 


\section{The most common challenges for Yemeni girls' education}

Looking at Yemeni girls' education in the reality the traditional image is shown the education for girl as a waste for time. Some Yemeni people still see the girl's main job is to work in the kitchen, as she is a mother or wife who does not have the decision and receives directions from the man. She is also awaiting the decision to marry without showing any opposition, even she was minor. Later, the woman turns into a device for reproduction and then the man begins searching for a second wife specially, if the offspring was a female. For that reasons, Yemeni woman's traditional image in the TV dramatic series is always negative one(Isabella 2018, P100).

The realistic image of Yemeni girl gives the viewer the reality of life that she still lives in Yemen. Yemeni girls work in agriculture and home, raising children and animals, transporting water from canals and storage tanks and other tasks that are not shared by men in general. Moreover, she is the conservative girl who is adhering to customs and traditions, she does not participate in decision-making and she works to fulfill the males' desires in the house. She also accepts to be a wife if she was minor or to be a second wife without taking into account the age difference between her and the man. In addition, she takes over the family, especially if the male dies due the revenge that is spreading intensively in Yemen (Mehrass, 2017. P253).

On the other hand, educated girls are viewed in society with scorn women specially those girls whom are working in public institutions. The working girl in the Yemeni males' eyes is that evil person who is searching for problems. Moreover, they see her as a wasteful person spends money on luxury goods, make up, the new fashion and the last worldwide songs etc...

From the foregoing, we conclude that the stereotype which is presented for Yemeni girl is negative. This shows us the prevailing social culture, both for the male as well as the female who is adapted to the situation and became a part of participial from rooted traditions in the country that it is still common for girls to take on what society details as female responsibilities, such as housework and childcare, and due to the fact that child labor does not include the use of domestic labor, female children are regularly ignored when examining statistics (CIA, Face book R).

\section{Constraints analysis}

When looking at the non-ideological dimensions, we clearly note that other factors contribute to the prevention of Yemeni women from education. Yemeni family's' culture and illiteracy for example: can be considered two basic dimensions that effect ongirl's education. Yemeni family prefers the girl to stay at home, given that her future is marriage, so she must learn to do housework. Moreover, many Yemeni family considers the girls' education at school as a disgrace. Yemen is still a developed country in which illiteracy rates are very high, especially among women. In Yemen we 
can notice many children are out of school. Most of them are female whom live in the countryside and urban areas(Al-Mekhlafy, 2008, P. 269).
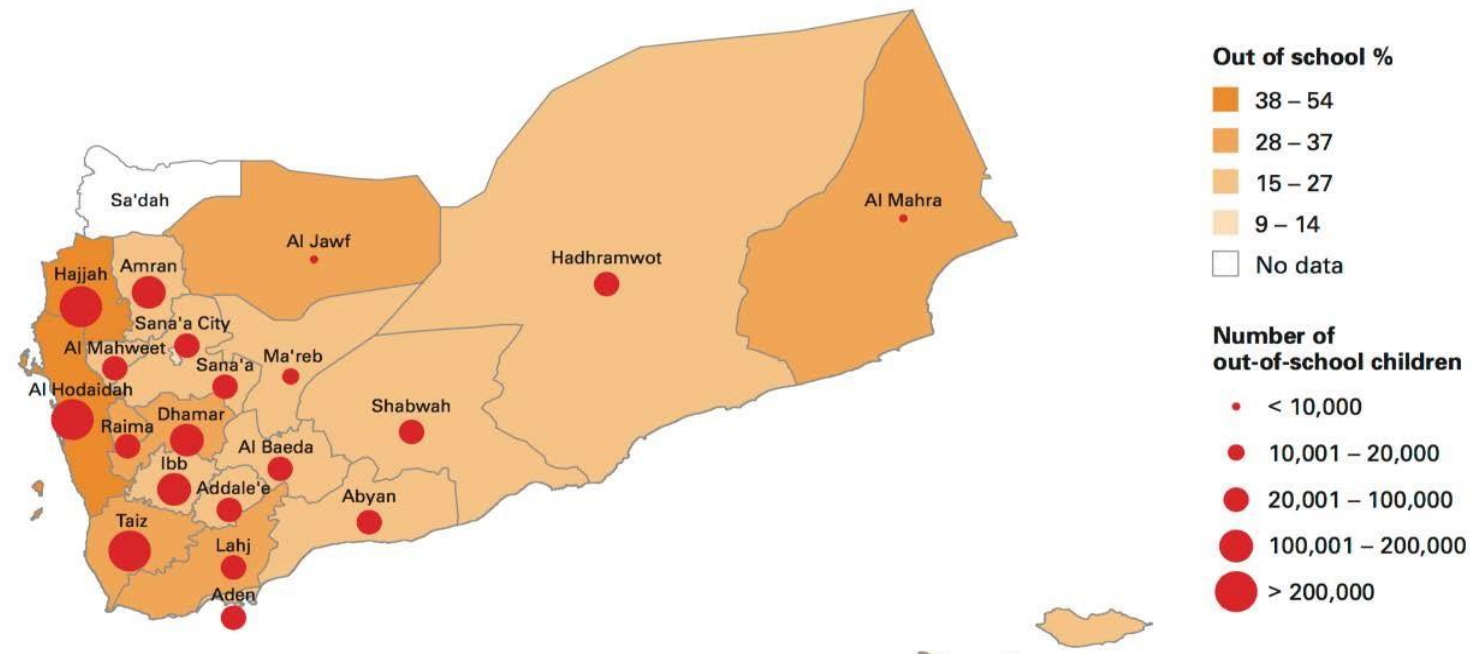

Source: United Nations Educational, Scientific and Cultural Organization (UNESCO) (2014).

Figure above depicts out-of-school children in Yemen's governorates by number (using a red dot) and as a percent (using gradients of orange). Although it may seem contradictory to see a large dot on a lighter colored governorate, it is important to keep in mind that the governorate could have an enormous population (UNESCO, 2014, P23).In addition, in Yemen it is still common for girls to take on what society details as female responsibilities, such as work in the farm, housework and childcare, and due to the fact that child labor does not include the use of domestic labor, female children are regularly ignored when examining statistics. Understandably this is an impediment to their education( world bank, 2010, P14).

The belief that women should not go to school and instead get married is the main reason why their education is cut short. In Yemen there are very strict gender roles, and there is an immense amount of pressure put on young girls to have children. Understandably, this is a reason some girls may drop out of school. In addition, the girl's marriage conflicts with her education, and the Yemeni family always prefers to choose an uneducated girl for her son.

Poverty and illiteracy are another constraint that makes women suffer a lot. Yemen country is one of the world's poorest countries. Many policies have been implemented to ensure that school is not just for those who can easily afford it, and the expansion of education projects have helped reach the poor in rural areas. In the 1990's, low-cost standardized schools were introduced, and this helped increase the number of schools available. This was a helpful response to the issue because threequarters of the Yemeni population live in remote and rural communities, so access to schools can be scarce and very difficult. 
The poverty constraint to girls' education goes hand in hand with the geographical constraints many girls face as rural poverty is overall higher in rural areas than in urban areas, in Yemen. For that, education is the best way to change a community for the better. It offers a plethora of benefits, not only for women, but the whole society in its different classes. Educating girls delays child marriages and child birth which in turn allows girls to earn money and build their self-esteem. Moreover, educating girls lowers the risk for domestic violence. Educating girls has also shown to help lifting families out of poverty as well as it helps mainly to change girls' stereotypical image in the society.(Mohamed, 2016, P400).

On the other hand, social culture among the society is developed through improving of an education and thus it will be reflected upon the girls' positions which are deserved in their society. Given that woman is a half of society, she has taken a large part in the career path of cultural structure of the society through education and improving its process continuously (Mehrass and others, 2017, P254-256). For that, Yemen has made headway in procuring a brighter future for girls. It has implemented a variety of programs that are improving girls' education. However, the difficulty will lie in ensuring these programs are sustainable.

\section{Final findings}

This study reveals that many causes enforce Yemeni girls to leave education the most famous challenges can be summarized as the following points:

- Yemeni girls face many challenges regarding to education and they need more help to overcome such this obstacle.

- Customs and traditions are the most challenges against Yemeni girls' education in Yemeni country.

- The poverty constraint to Yemeni girls' education goes hand in hand with the geographical constraints in rural and urban areas.

\section{Recommendations:}

- Yemeni girls need more attention by the whole world in order to help them to get a bright future.

- Given Yemeni girls more attention through early childhood development programs which help them to avoid their opinions to necessity of the education.

- Making a lot of intervention by government to encourage Yemeni girls in order to join schools beside helping them through many programs to motivate them developing their cognitive skills. 


\section{Conclusion}

Already some decades ago, Yemen tried to address the gender gap in education in order to make strides with their economy and their human development, but it has been suffering from political instability, thus impacting an economy that is continuously shrinking. As a result, to poverty most families are discouraged from sending their children, especially girls, to school and this has also been helped by the customs and traditions that favor the girl staying at home. In addition, some families marry off their daughters early to alleviate the extra financial burden. This, in turn, leads to no education or extremely high dropout rate among female students. The other result of these economic and political factors that also affects girls' education in Yemen is the scarcity of proper schools, classrooms and educational infrastructure as well as the illiteracy is widespread in Yemeni society.

On the other hand, conservative social and religious customs in Yemen discourage girls from attending mixed-gender classrooms or being taught by male teachers. Another important factor that affects girls' education in Yemen is underage marriage where most girls are married when they are minor. For that, Yemen is considered one of the countries that have the widest gender gaps, and although there have been sustained efforts to deal that hard problem, but that needs an intellectual revolution and economic support from international organizations. Moreover, it also needs to raise social awareness of the importance of girl's education in order to build a good society. In brief, Yemen needs self and international supports to overcome the education crisis entirely. It also needs everyone's cooperation in getting out of the situation that Yemen is suffering today and opening new pages to address all imbalances.

\section{References}

- Al-Mekhlafy, Tawfiq A. (2008). Strategies for Gender Equality in Basic and Secondary Education: A Comprehensive and Integrated Approach in the Republic of Yemen. In: Mercy Tembon and Lucia Fort (eds.) Girls' Education in the Twenty-First Century (Washington, DC: World Bank); (Chapter 16); available at:

https://siteresources.worldbank.org/EDUCATION/Resources/2782001099079877269/ 547664-1099080014368/DID_Girls_edu.pdf.

- United States, Central Intelligence Agency (CIA) (undated). The World Factbook Middle East: Yemen; available at:

https://www.cia.gov/library/publications/resources/the-worldfactbook/geos/ym.html.

- Isabella Grande (2018). School is Not Just for Boys: A Look at Girls' Education in Egypt and Yemen, Global Majority E-Journal, Vol. 9, No. 2.

-Mehrass, Amat Al-Khaleq O.; Intisar A. Ahmed; Abdullatif D. Ali and Abdulelah H. 
Al-Adhroey (2017). Early Marriage and Less Education as Independent Predictors for High Fertility in Yemen. Annals of Medical \& Health Sciences Research 7, Vol. 7, No. 4 (August).

-Mohamed, Mahmoud Abdel Hafez (2016). Targeting Poverty through Inclusive Education in Egypt: A Review of the Experiences of Some Developing Countries. Arab Journal of Administration, Vol. 36, No. 2 (December), pp. 400.

-United Nations Educational, Scientific and Cultural Organization (UNESCO) and United Nations Children's Fund (UNICEF) (2014). Yemen - Country Report on Outof-School Children. All in School: Middle East and North Africa Out-of-School Initiative. UNICEF Yemen Country Office (October); available at:

https://reliefweb.int/report/yemen/yemen-countryreport-out-school-children-enar.

-http: // www.Aljazeera. Net 17- 8-2011.

-World Bank (2010a). Poverty in Yemen. World Bank Website Resource, Feature Story (of January 20, 2010); available at: http://www.worldbank.org/en/news/feature/2010/01/20/poverty-in-yemen. 